Research article

\title{
New genera and problematic species in African Lithosiinae (Lepidoptera, Arctiidae, Lymantriidae)
}

\author{
Antonio DURANTE \\ Museo di Storia Naturale del Salento, via Europa, 95. 73021 Calimera, Italy. \\ E-mail: antonio.durante@msns.it
}

\begin{abstract}
This paper deals with some problematic species in the subfamily Lithosiinae. Two new monospecific genera are proposed: Parafrasura gen. nov. and Palaeugoa gen. nov. The former presents the following autapomorphies: tegumen strong and large; uncus long and slightly claviform; typical scaphium-gnathos complex. The latter presents as autapomorphies the disposition of the bands of the wings pattern, and the male genitalia shape. Asura naumanni Kühne, 2005 is considered incertae sedis within Lithosiinae and Asura phaeosticta Kiriakoff, 1958 is transferred to Euproctis Hübner, [1819] (Lymantriidae) (comb. nov.).
\end{abstract}

Key words. Lithosiinae, Lymantriidae, new genera, problematic species, Afrotropical Region.

Durante A. 2012. New genera and problematic species in African Lithosiinae (Lepidoptera, Arctiidae, Lymantriidae). European Journal of Taxonomy 22: 1-16. http://dx.doi.org/10.5852/ejt.2012.22

\section{Introduction}

Some studies on Lithosiinae in the African fauna led to the review of the genus Tumicla Wallengren, 1860 (Durante 2008) and to the description of the genus Afrasura Durante, 2009 (Durante 2009).

The examined material was constituted by species formerly included mainly in the genus Asura Walker, 1854 (Hampson 1900, 1914; Strand 1922; Seitz 1943; Vári et al. 2002; Kemal \& Koçak 2007), which is at the present limited to the Oriental and Australian regions (Common 1990; Edwards 1996; Holloway 2001; Durante 2009). In the course of the survey, several specimens could not be assigned to the genera Tumicla, Afrasura and Asura, being clearly different in genitalic morphology, though similar in external appearance.

The present contribution aims at providing a solid base of systematic knowledge on African Lithosiinae, even if some new taxonomic acts have not been supported by a large number of examined specimens, due to the objective scarceness of African material in the collections.

Some recent revisionary studies of the Noctuoidea (Fibiger \& Lafontaine 2005; Lafontaine \& Fibiger 2006; Mitchell et al. 2006; Zahiri et al. 2010) proposed several nomenclatural changes at suprageneric level, although a consensus view will probably still take some time to emerge. Until such time, this paper follows a conservative nomenclature leaving the rank of family to the Arctiidae; see also Conner (2009) for more extensive remarks. 


\title{
Material and methods
}

Techniques for dissecting, staining, mounting, and photographing are described in Durante (2008). Morphological terms follow Birket-Smith (1965), Klots (1970), Tikhomirov (1979), Kristensen (2003).

\author{
Abbreviations \\ BMARCT = Arctiidae collection of the BMNH; BMNH: The Natural History Museum (formerly \\ British Museum (Natural History)), London. \\ g.sl. $\quad=$ genitalia slide. \\ NHRS $\quad=$ Naturhistoriska Riksmuseet, Stockholm.
}

All the examined material is part of the BMNH collection, except for the type of Tumicla sagenaria (Wallengren, 1860) housed in the NHRS. The Asura naumanni type is in Lars Kühne's private collection (Kühne 2005).

\section{Results}

Phylum Arthropoda Latreille, 1829

Class Insecta Linnaeus, 1758

Order Lepidoptera Linnaeus, 1758

Family Arctiidae Leach, 1815

Subfamily Lithosiinae Billberg, 1820

Four cases of interesting and problematic species are hereafter reported. The fourth of them deals with a Lithosiinae species here transferred to the family Lymantriidae.

Parafrasura gen. nov.

\section{Type species}

Asura pectinella Strand, 1922, by present designation.

\section{Diagnosis}

Monospecific genus externally very similar to Afrasura and Tumicla. Differential characters: two basal bands on the forewings upperside (a single basal band in Tumicla); bipectinate antennae of the male (filiform or serrate in Afrasura and Tumicla); spur formula 0-4-4 (0-2-2 in Tumicla); coremata absent; uncus long and slender, clubbed (shorter, often curved, ending in a point in Afrasura and Tumicla); tegumen strong; scaphium well sclerotized; distal end of the valva undivided, with a finger-like process (valve clearly divided valva in Afrasura; a different kind of distal process present in Tumicla); presence of the processus distalis plicae (absent in Afrasura); vinculum without saccus; vesica with a cluster of very small and sparse thorns; no strong cornuti.

\section{Etymology}

The prefix "para", from ancient Greek, means "similar to" and indicates the probable relationship with the genus Afrasura. The gender of the new name is feminine.

\section{Description}

The descriptions of Bethune-Baker (1911) and Hampson (1914) of Asura pectinata are comprehensive enough with regard to external appearance of its body and wings (Fig. 1A-E). 


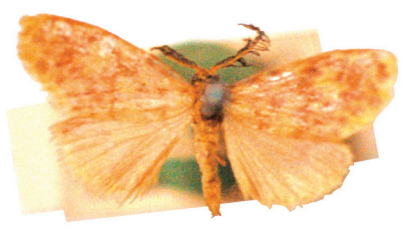

A

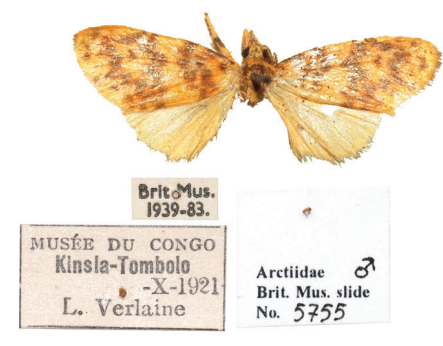

B

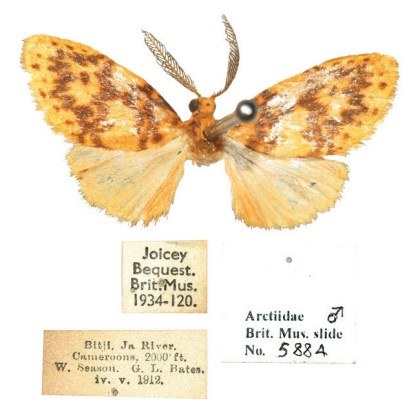

C
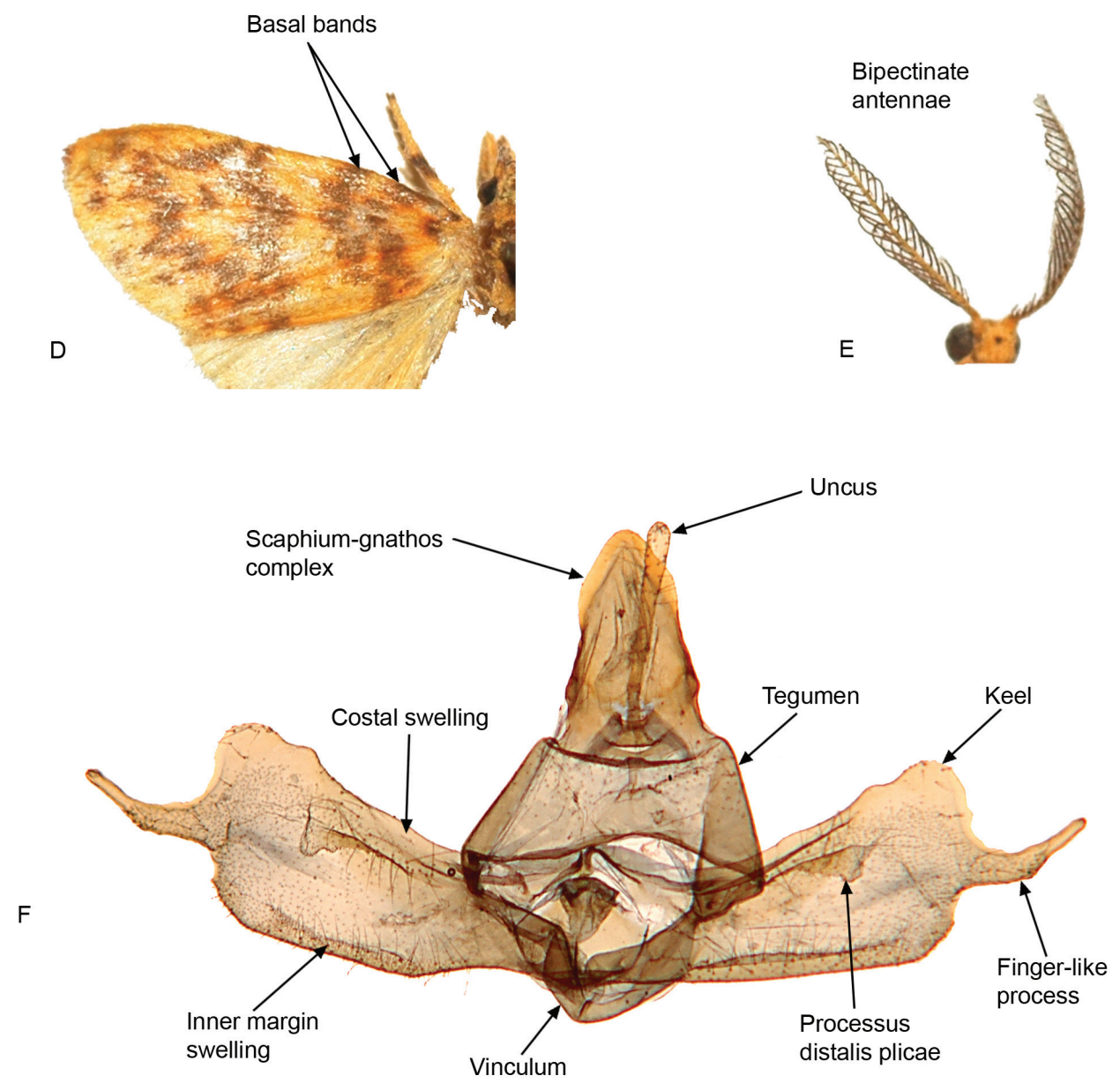

G

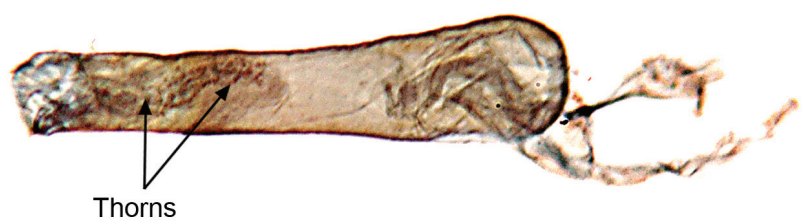

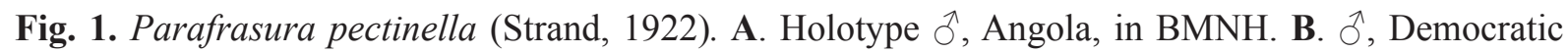
Republic of the Congo, in BMNH. C. O, Cameroun, in BMNH. D. Enlarged Fig. B, showing the basal bands of the forewing. E. Oे, head of Fig. C enlarged, showing the bipectinate antennae. F. ô genitalia, g.sl. BM ARCT 5741, Chad. G. Aedeagus, g.sl. BM ARCT 5741, Chad. 
Male AbDomen. With VII and VIII urites smaller than the previous ones. VIII sternum with anterior margin slightly waved; VIII tergum anterior margin with a bar-like reinforcement with two small apodemes at its lateral extremities.

Genitalia. (Fig. 1F-G) With uncus long and slender, claviform. Tegumen large and short, stronger than usually found in Asura-like genera (i.e. Asura, Afrasura, Tumicla). Posteriorly to the tegumen, two strong arms arise and suddenly meet together, forming a strong sclerotized structure (gnathos), which includes the sclerotized dorsal surface of the tuba analis (scaphium). Vinculum. Slender, semicircular, without saccus, tightly linked to the valvae. Anellus dorsally with a slightly sclerotized W-shaped transtilla, and ventrally with a quite large dome-shaped membranous juxta, not visible in the slide preparation.

VALVA. Slightly widening from the base to the distal margin, linked to the vinculum except for the costa. Two longitudinal swellings extending parallel from base to the distal 4/5: the first one just under the costal margin, the second one along the inferior margin (ala valvae of Birket-Smith 1965). At the apex, the valva possesses a keel-like enlargement; at the middle of the distal margin a finger-like process.

Aedeagus. Small, tubular, with a bulbous coecum. Vesica with sparse tiny thorns.

Female genitalia. These have not been directly examined, but the described characteristics (Kühne, 2007:365) seem to be exclusive, particularly the sclerotizations of the ostium bursae and the bag-shaped invagination proximad of the ostium.

\section{Remarks}

Asura pectinella Strand, 1922 was firstly described by Bethune-Baker (1911) in the genus Asura as A. pectinata (nom. praeocc.); the genitalia morphology, however, leads to the conclusion, that it should be included in a genus of its own. Already Kühne (2007) rightly separated this species in a group of itself, however leaving it in the genus Asura.

A new genus is here described after the examination of specimens from Western and Central Africa, whose size and wing pattern are very similar to Afrasura (Fig. 2A) and Tumicla (Fig. 2B). However the
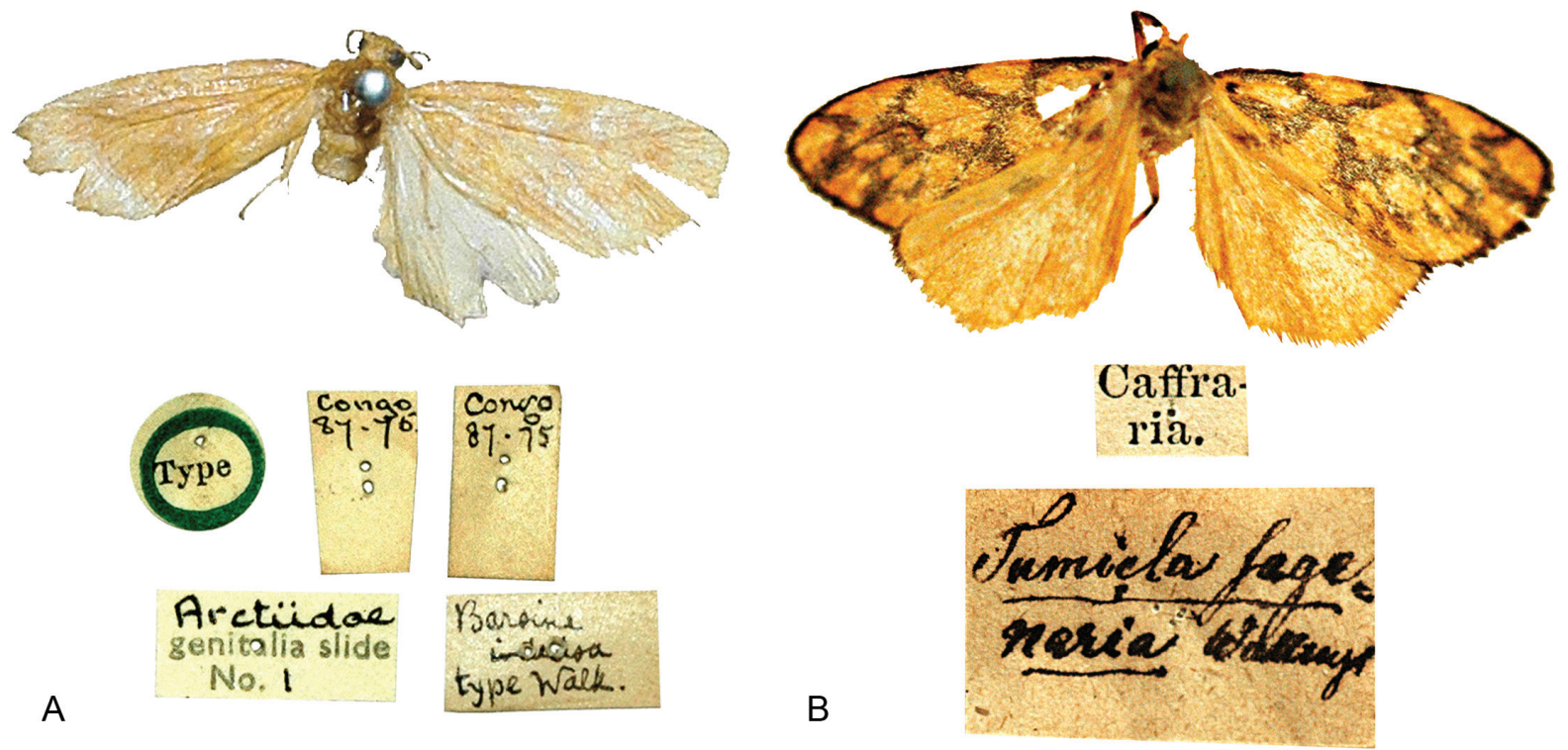

A
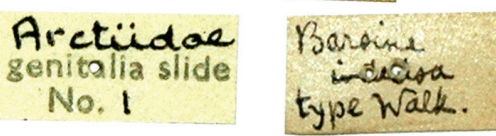

Fig. 2. - A. Afrasura indecisa, holotype $\widehat{\partial}$, Congo, in BMNH. - B. Tumicla sagenaria, holotype ${ }^{\lambda}$, South Africa, in NHRS. 
male bipectinate antennae and genitalic peculiarities are here considered strongly distinctive and have never before been observed in the aforementioned, probably related genera.

The new genus shows a wing venation and pattern very similar to that of Afrasura, so that the venation and the two basal bands are considered synapomorphic characters of the Afrasura-Parafrasura group.

Probable autapomorphies of Parafrasura are: tegumen strong and large; uncus long, slender, slightly claviform; shape of the scaphium-gnathos complex.

Other relevant characters are: male antennae bipectinate; female with short anterior apophyses and sinus vaginalis conformation.

Parafrasura pectinella (Strand, 1922) comb. nov.

(Fig. 1A-E)

Asura pectinella Strand, 1922: 793.

Asura pectinata Bethune-Baker, 1911: 537.

\section{Diagnosis}

Species characterized by the strong scaphium firmly connected with the gnathos arms; valva with digitiform process at the middle of the outer margin; aedeagus small, tubular, with a bulbous coecum; vesica with sparse tiny thorns.

\section{Type locality}

Angola, N'Dalla Tando (holotype ổ examined, genitalia not dissected, in BMNH).

\section{Material examined}

CHAD: § Arct. g.sl. n. 5741 BMNH. CAMEROUN: đิ Arct. g.sl. n. 5884 BMNH. DEMOCRATIC REPUBLIC OF THE CONGO: $\curvearrowright$ Arct. g.sl. n. 5755 BMNH.

\section{Distribution}

Asura pectinella was originally described by Bethune-Baker (1911) from Angola; Hampson (1914) and Strand (1922) report the species from Cameroun; to these countries, the Chad and the Democratic Republic of the Congo (BMNH collection) are added here.

\section{Description}

See under the generic account.

Palaeugoa gen. nov.

\section{Type species}

Xanthetis spurrelli Hampson, 1914, by present designation.

\section{Diagnosis}

Forewings larger than in Xanthetis, as observed after comparison with the type species X. luzonica (Felder, 1875), with rounded apex. Wing pattern superficially similar to Afrasura, but more punctuate and with different distribution of bands (see differential diagnosis below). Male genitalia resembling Eugoa Walker, 1857 (type species Eugoa aequalis Walker, 1857 from Borneo) with dorsal processes of the tegumen and short and stout uncus, but differing in valvae structure. 

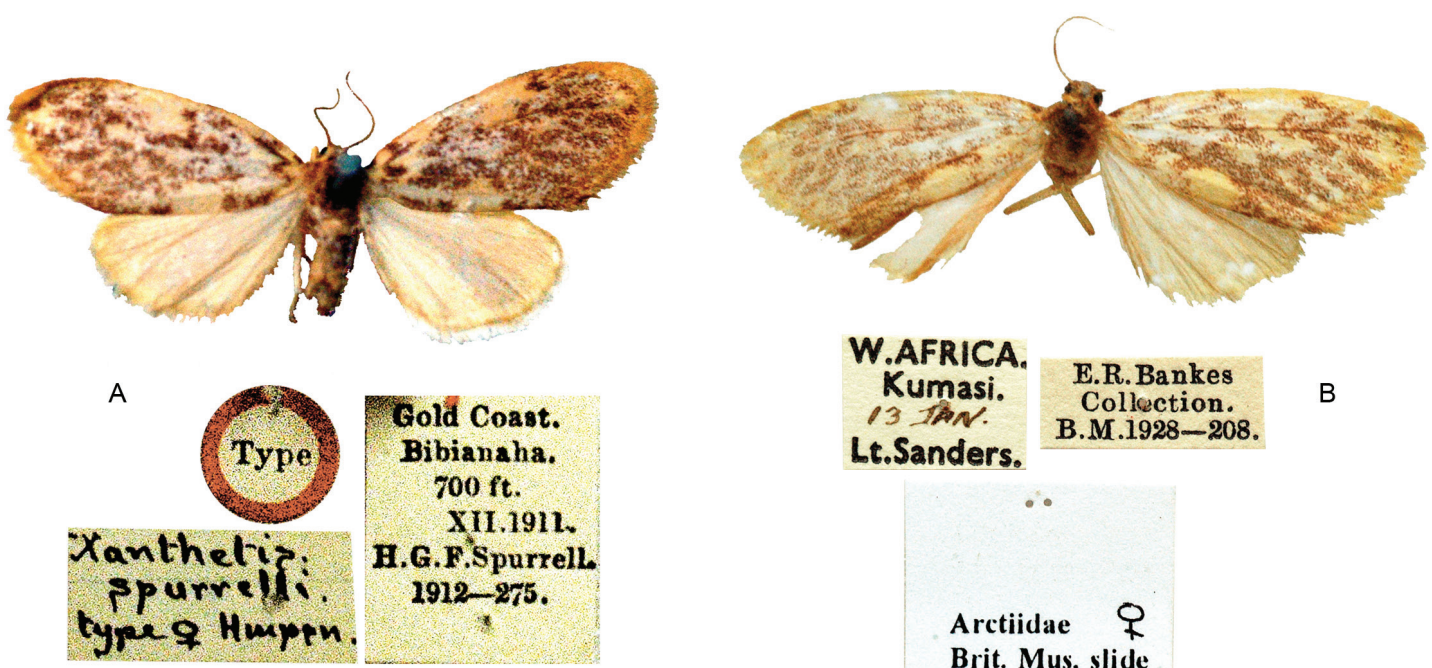

Arctiidae $\$$

Brit. Mus. slide

No. 57.56

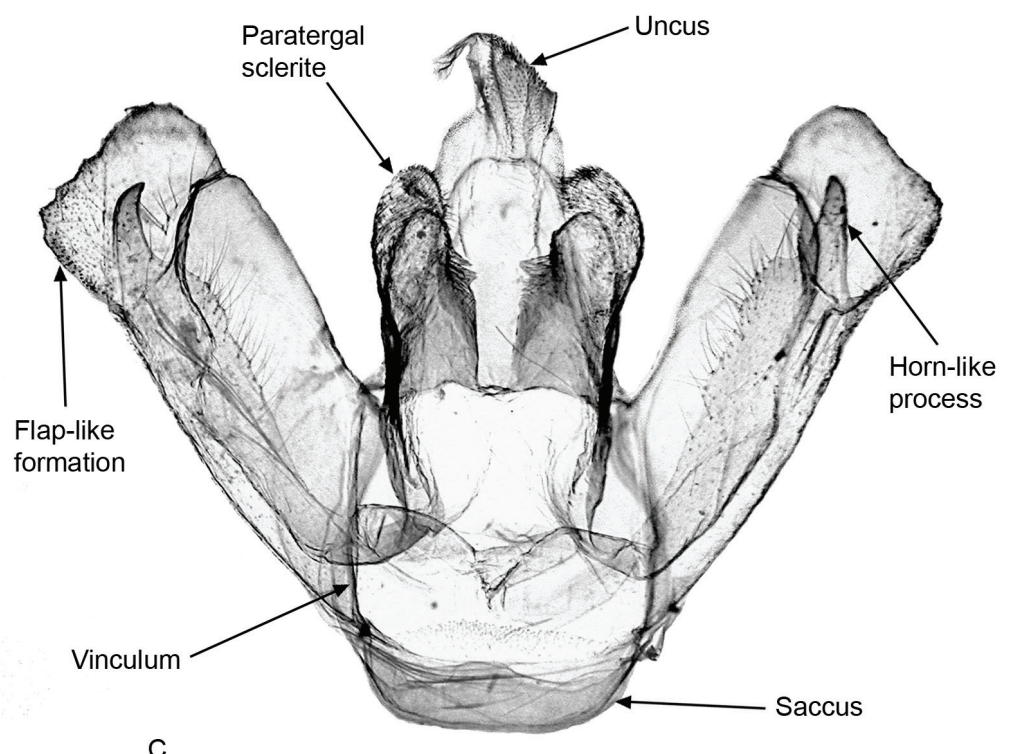

C
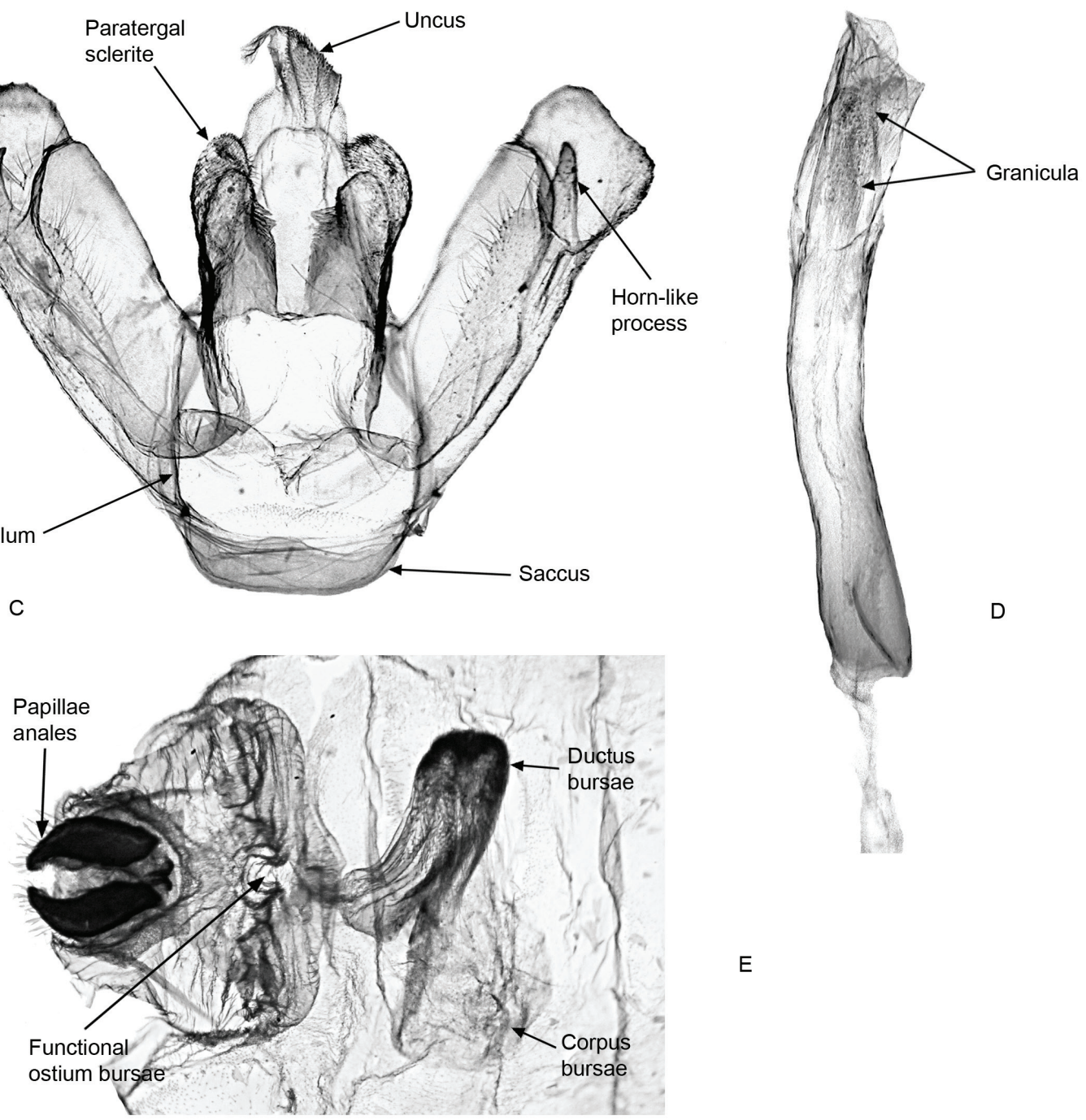

E

Fig. 3. Palaeugoa spurrelli (Hampson, 1914). A. Syntype + , Ghana, in BMNH. B. $\odot$, Ghana, in BMNH. C. ô genitalia, g.sl. BM ARCT 301, Ghana. D. Aedeagus, g.sl. BM ARCT 301, Ghana. E. $q$ genitalia, g.sl. BM ARCT 5756, Ghana. 


\section{Etymology}

The name Palaeugoa has no phylogenetic implications, it simply refers to its Western Palaeotropical distribution. The gender is feminine.

\section{Description}

The description of Hampson (1914) about the external features is very accurate (Fig. 3A-B).

Male genitalia. (Fig. 3C-D) With a more robust general structure than in Asura and Afrasura. Uncus short but large; tegumen with conspicuous paratergal sclerites; vinculum slender with a large and shallow saccus; valvae rectangular with straight costa turning inwards at three-quarters. Ala valvae (sacculus) membranous as long as the costal margin, ending in a strong horn-like process. The proximal threequarters of valva surmounted by a distal flap-like formation with a slightly waved margin.

Aedeagus. Tubular, slender, slightly curved; vesica with a sparse group of granicula (see Tuxen 1970, for grammatical gender).

FEMALE PHEROMONE GLAND. With a large base and two anterior quite deep lobes.

Female genitalia. (Fig. 3E) With sinus vaginalis anteriorly delimited by posterior margin of the seventh sternite, forming a slightly sclerotized plica. Posteriorly it is delimited by the scarcely sclerotized eighth sternite, whose anterior margin forms a short backward plica. This is interrupted medially by a funnelshaped excavation that probably serves as a functional ostium bursae and antrum, whereas the true ostium bursae lies deeper at its anterior end, membranous, concealed by the VII sternum plica.

DUCTUS BURSAE. After a very short, narrow and membranous portion, enlarging in a sac-like structure (cervix?) more sclerotized and transversally displaced with scattered spines inside.

CoRpus BURSAE. Spherical, membranous, without signa; ductus seminalis arising caudally from it. Anterior apophyses short, posterior apophyses long and slender. Papillae anales ventrally concealing two small pseudopapillae (sensu Maes 1984).
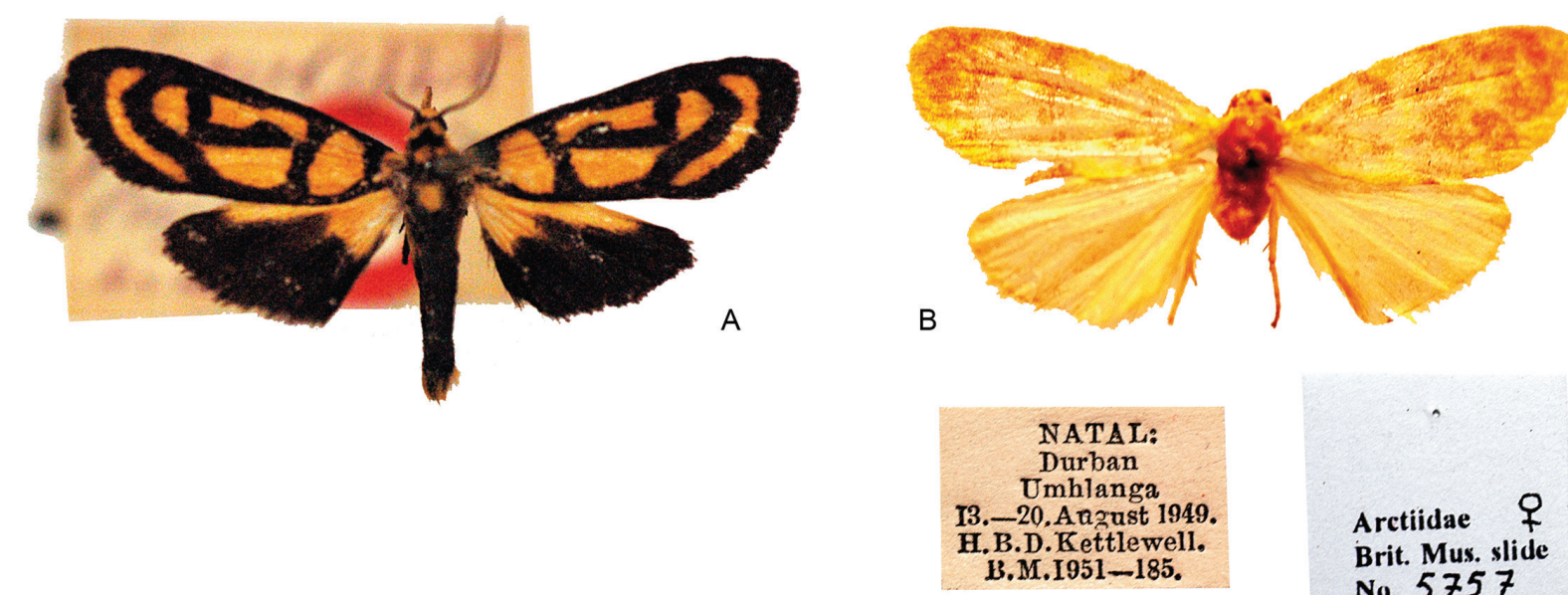

Arctiidae $q$

Brit. Mus. slide No. 5757

Fig. 4. - A. Xanthetis luzonica (Felder, 1875), holotype ô, Philippines, in BMNH. - B. Afrasura ichorina (Butler, 1877), , , South Africa, in BMNH. 


\section{Remarks}

Xanthetis spurrelli from the Gold Coast is a problematic species; it was not placed in the genus Afrasura Durante, 2009, despite of its similar appearance.

The genus Xanthetis Hampson, 1900 was described based on the type species X. luzonica (Fig. 4A) from the Philippines and on X. ichorina (Butler, 1877) (Fig. 4B) from Natal, which share a similar wing venation, but differ in wing shape and pattern, and in the genitalic morphology. On the basis of these differences ichorina was transferred to Afrasura by Durante (2009), whereas luzonica is retained in Xanthetis, a genus here considered at least apparently similar to the Australian Asura (the question whether the similarity is due to shared common ancestry is not discussed herein).

The description of spurrelli in Hampson (1914) starts with the statement of the coincidence of veins 3 and 4 in the hindwings, whereas they are stalked in luzonica. It should be remarked once more (Durante 2004) that this character is inconstant at least among the Lithosiinae, in fact veins 3 and 4 are coincident only in the right hindwing of the examined female of spurrelli from Kumasi, whereas they are stalked in the left hindwing (see also the case of Afrasura ichorina in Durante 2009).

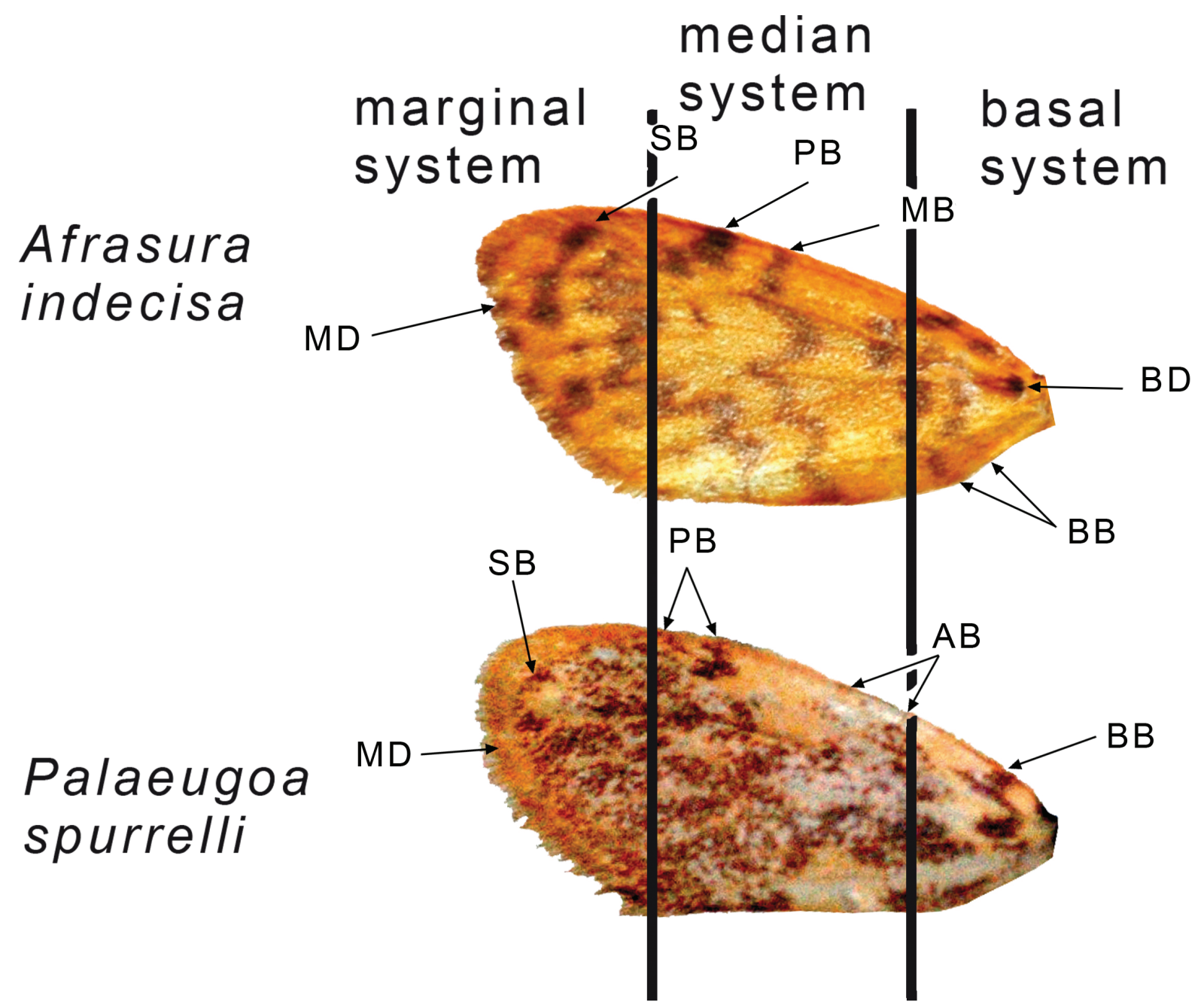

Fig. 5. Forewing of Afrasura indecisa (top) and Palaengoa spurrelli (bottom) and their related pattern symmetry systems. $\mathrm{AB}$, antemedian bands; $\mathrm{BB}$, basal band(s); $\mathrm{BD}$, basal dot; $\mathrm{MB}$, median band; $\mathrm{MD}$, marginal dots; $\mathrm{PB}$, postmedian band(s); SB, submarginal band. 
The new genus is here proposed due to the instability of the venational characters used by Hampson (loc. cit.) to delineate the taxa, differences in wing pattern and markedly different genitalic morphology.

It could be significant to compare the wings pattern of Palaeugoa gen. nov. to the one of Afrasura.

In their general appearance, the two genera present a quite similar pattern, suggesting a similar response to the selective pressure; however, the substantial differences in the position of the different elements of the pattern and differences in genitalic morphology indicate that they are in fact not closely related.

In fact, Afrasura presents a sequence of band systems that is well defined and shared by all of its species, with the presence of two basal bands considered an apomorphic character (Durante 2009). The bands correspond as follows:

\begin{tabular}{|c|c|c|}
\hline Afrasura & Palaeugoa & Symmetry systems \\
\hline two basal & one basal & basal system \\
one median & two antemedian & median system \\
one postmedian & two postmedian & median system \\
one submarginal & one submarginal & marginal system \\
\hline
\end{tabular}

The different number of bands in the basal and median systems is noteworthy (Fig. 5), and the relative position of the corresponding bands in different areas of the wings is emphasized (i.e. the basal band in Palaeugoa is slightly more basally positioned than the more proximal of the two basal bands in Afrasura, and the two antemedian (AB) bands of the former are more proximally located than the single band (MB) of Afrasura). A potential inference of this is that the respective positions of wing bands within the symmetry systems of Afrasura and Paleugoa are not homologous.

The second important character complex that should be examined is the genitalic apparatus.

The differences between Asura and Afrasura are both in the general appearance and in the details: the uncus shape of Palaengoa is never seen in Asura and Afrasura, the tegumen of the former bears two very strong processes (paratergal sclerites), the saccus is very large and shallow, valva with well separated dorsal (supravalva) and ventral (ala valvae) regions ending together in a flap-like structure (perhaps corresponding to the cucullus of Kôda 1987), whereas, in the latter two genera, the paratergal sclerites are only weakly developed, the saccus is deeper and more narrow, valva with the two regions hard to delimit, apart from their two terminal processes. A similar condition is seen in Tumicla, with the exception of the valva, which is even more simple (see Durante 2008).

A more similar genitalia structure is found in the Oriental genus Eugoa (type species Eugoa aequalis (Walker, 1857), Fig. 6A). This genus has recently been revised by Holloway (2001) for the Bornean fauna, but some uncertainties still remain; in the present work Eugoa is considered in a very strict sense taking into account only the type species and the very similar Eugoa trilacunata Holloway, 2001, even if some other species could be included (e.g. Eugoa bipunctata (Walker, 1862)). Essentially, similarities in the male genitalia of the two genera (Palaeugoa and Eugoa) are limited to the short uncus and the well-developed processes of the tegumen, otherwise they are quite different. In Eugoa the uncus itself is of a different shape and surmounted by strong setae (absent in Palaeugoa); the saccus is practically absent; the valvae represent the most diverging character: they are entire, bearing on the inner margin long costally directed setae, with the sacculus not ending in a distal process (Fig. 6B). 
Some additional observations are useful in separating the two genera: the forewing shape is rectangularish in Eugoa (quite rounded in Palaeugoa); in Eugoa the pattern consists of dark fasciae on white-grey ground; forewings venation with Sc anastomosing with R; Rs1 free; the stalked pairs (Rs2+Rs3), (Rs4+M1) and (M2+M3); whereas in Palaeugoa the pattern is as seen in the description above, the anastomosis is lacking, vein Rs2 is absent, all veins are free, but Rs3+Rs4 are stalked.

Taking into account these differences, a close relationship between the two genera is at least doubtful, even though they are referable to the same tribe.

Holloway (2001) did not include Eugoa in any described tribus (according to Bendib \& Minet 1999), similarly Palaeugoa is at the moment unassigned.
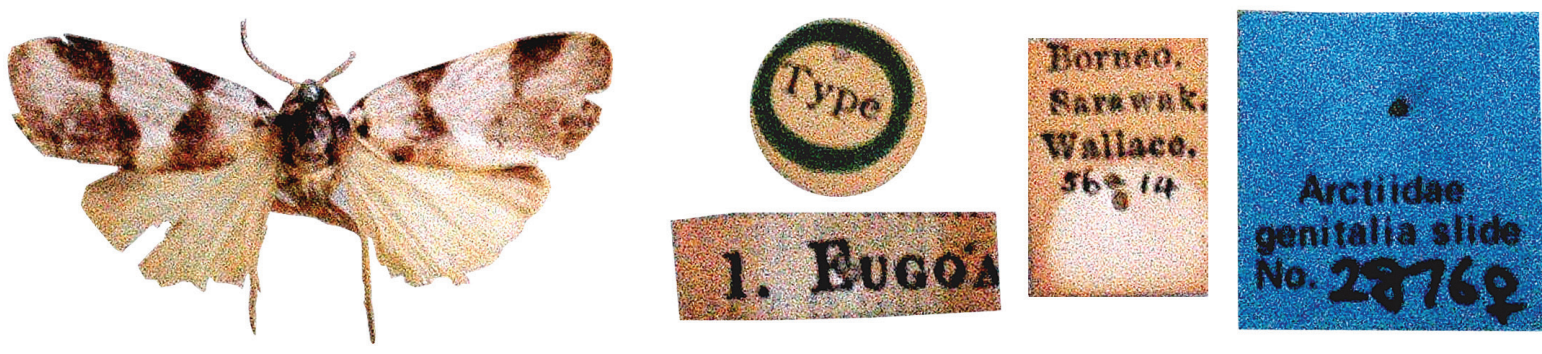

A
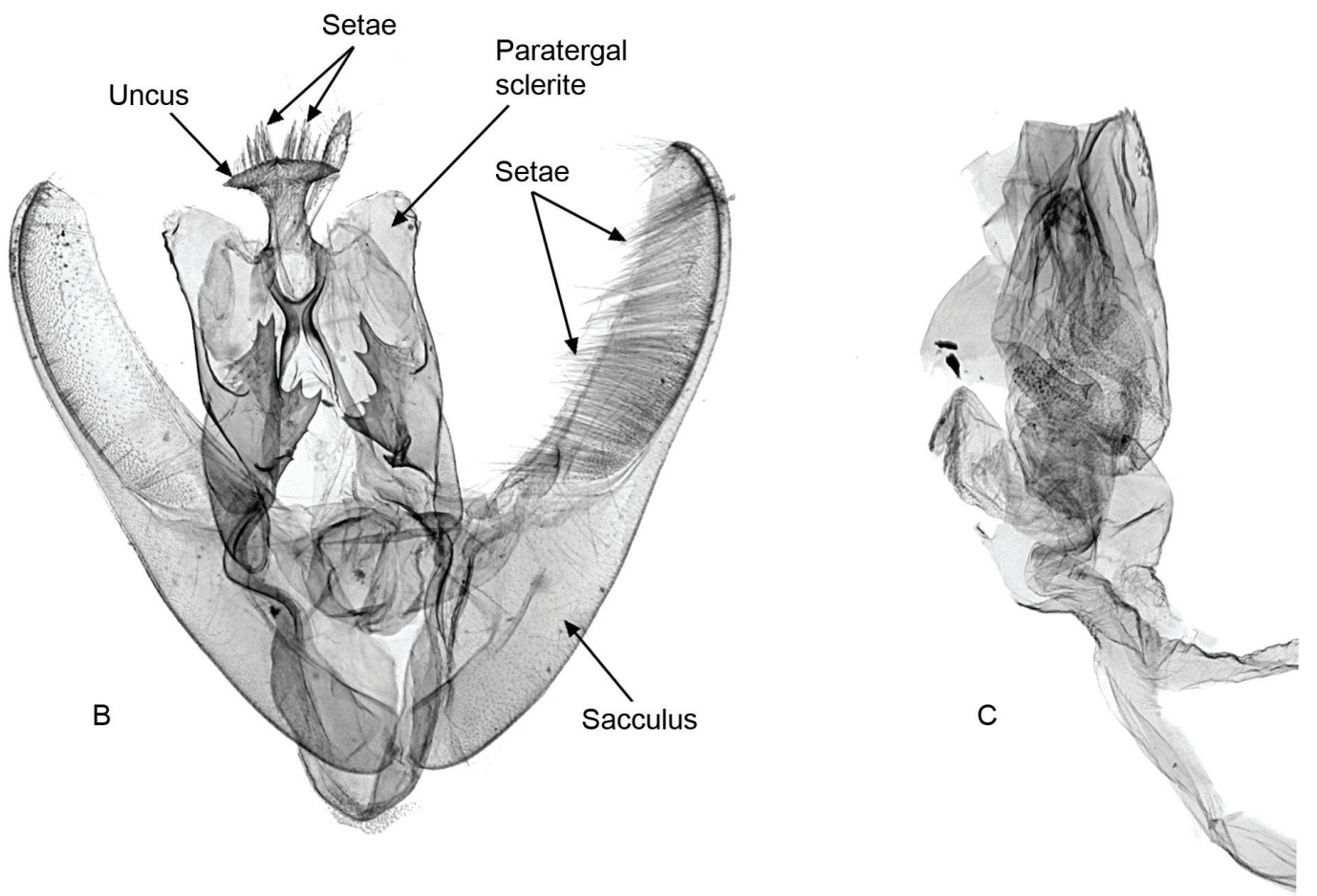

Fig. 6. Eugoa aequalis (Walker, 1857). A. Holotype ${ }_{+}$, Borneo, in BMNH. B. ô genitalia, g.sl. BM ARCT 5057, Borneo. C. Aedeagus, g.sl. BM ARCT 5057, Borneo. 
Palaeugoa spurrelli (Hampson, 1914) comb. nov.

(Fig. 3A-E)

Xanthetis spurrelli Hampson, 1914: 728.

\section{Diagnosis}

This species is easily separable from all members of the genus Afrasura on account of its highly distinctive genitalic morphology (uncus, valvae and aedeagus shape). In particular, the composite structure of the valva and its flap-like distal end permit ready distinction from Eugoa aequalis.

\section{Material examined}

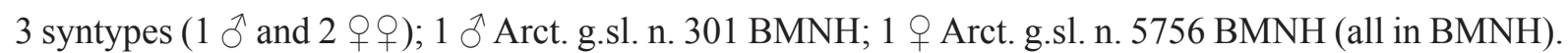

\section{Type locality}

GOLD COAST [Ghana], Bibianaha (1 $\widehat{\partial}, 2$ q $q$ syntypes examined, abdomens not dissected, in BMNH).

\section{Description}

See under the generic account.

\section{Distribution}

Ghana.

“Asura” naumanni Kühne, 2005

Asura naumanni Kühne, 2005: 486-493.

\section{Diagnosis and description}

See the original description (Kühne 2005).

\section{Material examined}

Only known from the original description.

\section{Type locality}

RWANDA, Akagera riv., S Kibungo/Ibanda-Makera (holotype $\delta$ not examined, in the author's private collection).

\section{Remarks}

"Asura" naumanni is a further problematic species. In fact, after the revision of the afrotropical species formerly included in Asura, leading to their inclusion in the genera Tumicla and Afrasura (Durante 2008, 2009), it is difficult to assign this species to one of these genera or to Asura itself.

The external aspect of this species markedly differs from Afrasura and Tumicla as regards to distribution, shape, origin and development of the wing pattern bands. Male genitalia confirm such differences, mainly the very short uncus and the general shape of the valvae.

Judging from the illustration (Kühne 2005: 493), the processus distalis plicae seems to be present and the vesica seems to have two clusters of strong thorns without a single big cornutus, as opposed to Afrasura, for which they are distinctive characters. 
At the moment this species should be considered as being incertae sedis within the Lithosiinae, pending a comparison with other genera.

Female genitalia are neither described nor figured in the original work.

\section{Distribution}

Rwanda, Uganda, Kenya.

Euproctis phaeosticta (Kiriakoff, 1958) comb. nov.

(Fig. 7A-H)

Asura phaeosticta Kiriakoff, 1958: 4.

\section{Diagnosis}

Male genitalia (figs. 7D-E) with valvae not visibly divided into supravalva and ala valvae; the latter presents a small process at half of its inner margin (also described by Kiriakoff 1958, but not illustrated in the accompanying picture); the uncus is clearly more robust and large at the base than it is in Asura and Afrasura; vesica without cornuti.

Female abdomen with A7 prominent and weakly sclerotized; A8 generally membranous, but eighth sternum sclerotized with a median incision of the caudal margin, whereas the anterior margin extends to wrap the sinus vaginalis (in Asura and in Afrasura the eighth segment is small and membranous).

Ductus bursae stiff and short (Fig. 7F), serving as point of origin of the ductus seminalis (in Asura and Afrasura the ductus seminalis arises from the cervix bursae). Anterior apophyses extremely reduced; posterior apophyses missing. The structure of abdominal segments 9-10 complex is plurilobate, with two big ventral papillae, an unpaired dorsal papillary structure, two median caudal clubbed lobes, at which base, in latero-ventral position, two other small papillary processes arise (Fig. 7G).

Finally, it should be noted that the apodemes of the sternite of A2 are short and stout (Fig. 7H), instead of long and slender as normally in the tribus Nudariini (Bendib \& Minet, 1999).

\section{Material examined}

UGANDA, Ruwenzori: ${ }^{\Uparrow}$ Arct. g.sl. n. 5740 BMNH. TANZANIA: ㅇ Arct. g.sl. n. 5751 BMNH, (both in BMNH).

\section{Type locality}

Uganda (holotype $\widehat{\sigma}$ examined, lacking the end of the abdomen, in BMNH).

\section{Distribution}

Uganda, Ruwenzori. Tanzania (BMNH).

\section{Remarks}

Examination of the male genitalia of this species shows that it does not belong to Asura or Afrasura, but is a representative of the Lymantriidae, which is also confirmed by the presence in males of 3-1 divergent setae at the apex of the ramus of each flagellomere (Kitching \& Rawlins 1999: 386); by the plurilobate structure of abdominal segments 9-10 complex (papillae anales and pseudopapillae; see Maes 1984); and by the absence of female pheromone dorsal glands between A8 and A9 (see Holloway 1988; Bendib \& Minet 1998). 
A

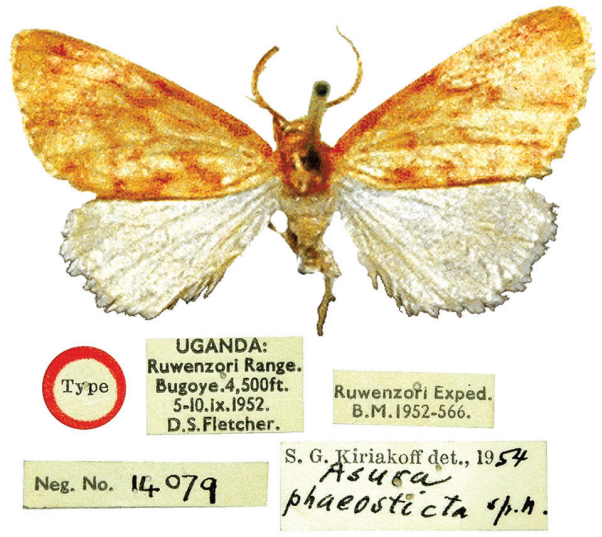

B

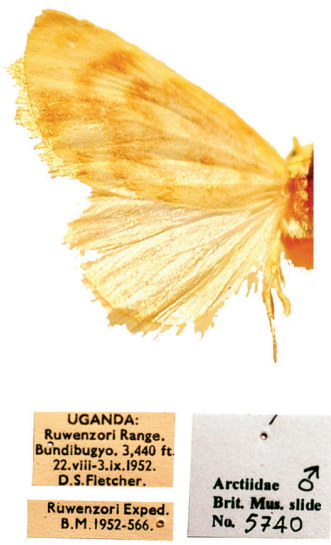

C

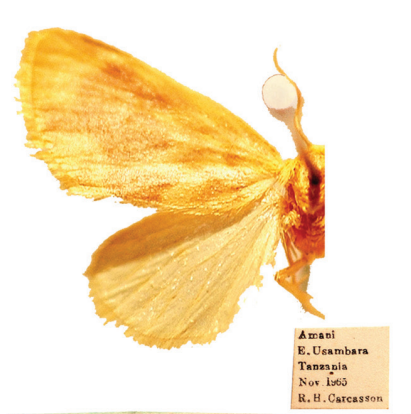

RSURA.

PHAEOSTICTA

Kisiak Ts $\begin{aligned} & \text { Aretidae } \\ & \text { Brit Mus slide } \\ & \text { Na. } 5751\end{aligned}$
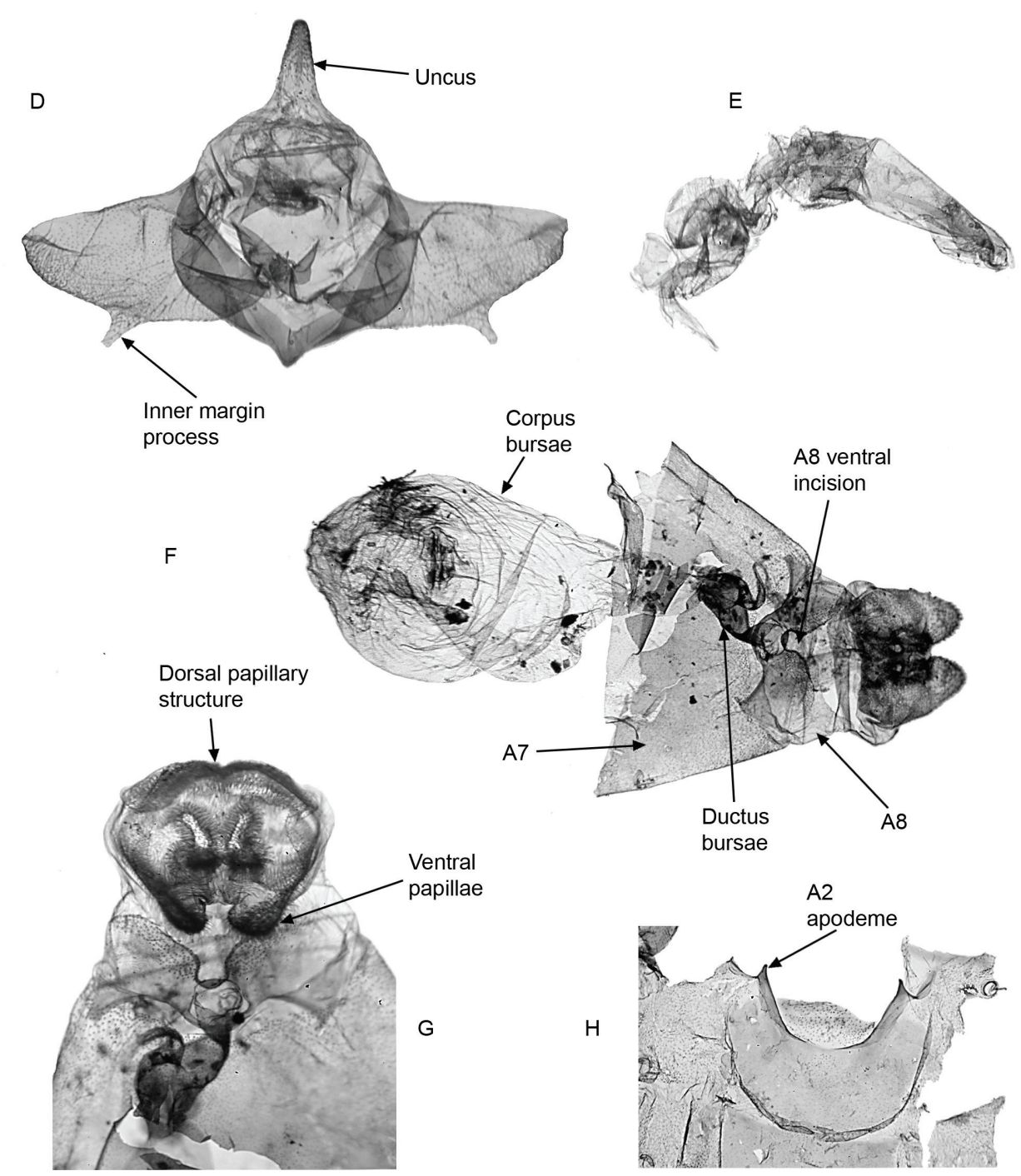

Fig. 7. Euproctis phaeosticta (Kiriakoff, 1958) comb. nov. A. Holotype đ̂, Uganda, in BMNH. B. ô, Uganda, in BMNH. C. क्, Tanzania, in BMNH. D. ô genitalia, g.sl. BM ARCT 5740, Uganda. E. Aedeagus, g.sl. BM ARCT 5740, Uganda. F. $q$ genitalia, g.sl. BM ARCT 5751, Tanzania. G. + , ventro-caudal view of papillae anales, g.sl. BM ARCT 5751, Tanzania. H. $\widehat{\jmath}$, sternum A2 apodemes, g.sl. BM ARCT 5740, Uganda. 
The generic position of this species is not very clear. According to the wing venation, similar to Afrasura, and without considering the anastomosis between veins 11 and 12 in phaeosticta, it could be assigned to such genera as Leucoma Hübner, 1822 or Naroma Walker, 1856, however the genitalia are clearly different. The Malagasy genus Leptepilepta Collenette, 1929 (Griveaud 1977) has been considered too, whose genitalia are quite similar, mostly with regard to the shape of the valva which possesses a similar process at the inner margin. It has been, however, excluded on account of the general colour and shape of the wings, the presence of an areola in the forewing venation, the geographic distribution (only Madagascar), the female genitalia being unknown, in addition to some differences of the male genitalia.

Lastly, but not without some reservations, the genus Euproctis Hübner, [1819] has been selected since it includes species with similar general appearance, a large geographical range, and similarity of some male genitalia (e.g. E. lemuria (Hering, 1926) or E. imerina Griveaud, 1977) (particularly the general similarity of the uncus, the valvae and the aedeagus).

\section{Discussion}

The revisionary work on African Lithosiinae, and on the whole Arctiidae as well, is just in its early stage (see Weller et al. 2009 for a quick outline) and it is normal that papers such as the present will formulate questions rather than find solutions.

Many researchers will agree on the fact that several ways will be explored before reaching a sufficiently complete knowledge of this group. The creation of new genera is believed necessary when a large distance in morphological characters is discerned between different species, even if clear autapomorphies are not established at the same time. The expected better knowledge of new morphological traits together with molecular data, ecological information and life cycle description will single out new apomorphies agreed on by most scientists and founded on a more objective and large basis. It is probable that in Africa, like in other regions (such as in the Oriental Tropics), the Lithosiinae had a quite strong adaptive radiation with many species becoming so specialized that they reach what we consider generic level. This could explain the quite high number of monotypic genera.

At the present, the first goal should be a general knowledge of the main African groups for an initial realistic systematic account.

Many cases like the cited Asura naumanni or some others that are not reported for lack of direct knowledge (i.e. Asura friederikeae Kühne, 2007 and Asura pinkurata Kühne, 2007) are probably better placed in monotypic genera to emphasize their morphological and probably phylogenetic distance from the already known genera.

\section{Acknowledgements}

The author thanks Martin Honey, The Natural History Museum, London, UK, for permission to study and dissect the specimens housed there; and Bert Gustafsson, Naturhistoriska riksmuseet, Stockholm, Sweden, for making the holotype of Asuroides sagenaria available.

He also thanks Martin Kruger, Transvaal Museum, Pretoria, South Africa, an anonymous reviewer, and Koen Martens, University of Ghent, Belgium for acutely reviewing the draft.

Finally he thanks Daniela Errante and Emanuele Sponsiello, Oxford Institutes, Lecce, Italy, for linguistic suggestions. 


\section{References}

Bendib A. \& Minet J. 1998. Female pheromone glands in Arctiidae (Lepidoptera). Evolution and phylogenetic significance. Comptes Rendus de l'Académie des Sciences, 321: 1007-1014.

Bendib A. \& Minet J. 1999. Lithosiine main lineages and their possible interrelationships. I. - Definition of new or resurrected tribes (Lepidoptera: Arctiidae). Annales de la Société entomologique de France (N.S.), 35 (3-4): 241-263.

Bethune-Baker G.T. 1911. Descriptions of new African Heterocera. The Annals and Magazine of Natural History, vol. 7, VIII series: 530-552.

Birket-Smith J. 1965. A revision of the West African Eilemic Moths, based on the Male Genitalia. (Lep., Arctiidae, Lithosinae; incl. gen. Crocosia, Eilema, Lithosia, Pelosia, Phryganopsis a. o.). Papers from the Faculty of Science. Series C (Zoology) No. 1, Haile Sellassie I University, Addis Ababa.

Common I.F.B. 1990. Moths of Australia. Melbourne University Press, Melbourne.

Conner W.E. 2009. Tiger Moths and Woolly Bears. Behavior, ecology, and evolution of the Arctiidae. Oxford University Press, Oxford.

Durante A. 2004. I Lepidotteri del Delta del Niger (Sesto contributo) (Arctiidae, Lithosiinae). Lambillionea, CIV, 4: 717-722.

Durante A. 2008. Asuroides, a new genus of lithosiine moths (Lepidoptera, Arctiidae, Lithosiinae). Zootaxa, 1713: 53-68.

Durante A. 2009. Revision of the Afrotropical species of Asura Walker, 1854 (Lepidoptera: Arctiidae, Lithosiinae), with the description of a new genus. Zootaxa, 2280: 27-52.

Edwards E.D. 1996. Arctiidae. In: Nielsen E.S., Edwards E.D. \& Rangsi T.V. (eds) Checklist of the Lepidoptera of Australia, Monographs on Australian Lepidoptera: 278-286. CSIRO, Clayton.

Fibiger M. \& Lafontaine J.D. 2005. A review of the higher classification of the Noctuoidea (Lepidoptera) with special reference to the Holarctis fauna. Esperiana, 11: 7-92.

Griveaud P. 1977. Insectes Lépidoptères: Lymantriidae. Faune de Madagascar 43: 1-588.

Hampson G.F. 1900. Catalogue of the Lepidoptera Phalaenae in the British Museum. Arctiadae (Nolinae, Lithosianae). Vol. II. British Museum (Natural History), London.

Hampson G. F. 1914. Catalogue of the Lepidoptera Phalaenae in the British Museum. Supplement. Volume I. British Museum (Natural History), London.

Holloway J.D. 1988. The Moths of Borneo [Part 6]: family Arctiidae, subfamilies Syntominae, Euchromiinae, Arctiinae, Noctuidae misplaced in Arctiidae (Camptoloma, Aganainae). Southdene, Kuala Lumpur.

Holloway J.D. 2001. The Moths of Borneo [Part 7]: Arctiidae, Lithosiinae. Malayan Nature Journal, 55: 279-486.

Kemal M. \& Koçak A.Ö. 2007. Synonymous Checklist of the South African Lepidoptera. CESA Publications on African Lepidoptera, 2, Musée royal de l'Afrique centrale, Tervuren.

Kiriakoff S.G. 1958 Ruwenzori Expedition, 1952, vol. I, 2, Arctiidae (except Nolinae), Thyretidae and Notodontidae. Trustees of the British Museum, London.

Kitching I. J. \& Rawlins J. E. 1999. The Noctuoidea. In: Kristensen N.P. (ed.), Lepidoptera, Moths and Butterflies, vol. 1, Evolution, Systematics, and Biogeography, part 35: 355-401. De Gruyter, Berlin New York.

Klots A.B. 1970. Lepidoptera. In: Tuxen S.L. (ed.), Taxonomist's glossary of genitalia in insects. Ed. II: 115-130. Munksgaard, Copenhagen. 
Kôda N. 1987. A generic classification of the subfamily Arctiinae of the Palaearctic and Oriental regions based on the male and female genitalia (Lepidoptera, Arctiidae). Part I. Tyô to Ga, 38 (3): 153-237.

Kristensen N.P. 2003. Skeleton and muscles: adults. In: Kristensen N.P. (ed.), Lepidoptera, Moths and Butterflies, vol. 2, Morphology, Physiology, and Development, part 36: 39-131. De Gruyter, Berlin New York.

Kühne L. 2005. Neue Taxa und neue Synonyme afrikanischer Arctiidae (Lepidoptera). Lambillionea, CV, 3: 486-493.

Kühne L. 2007. Beschreibung neuer Flechtenbärenarten aus Afrika nebst taxonomischen Anmerkungen (Arctiidae: Lithosiinae). Esperiana Memoir, 3: 353-394, pls. 44, 45.

Lafontaine J.D. \& Fibiger M. 2006. Revised higher classification of the Noctuoidea (Lepidoptera). The Canadian Entomologist, 138: 610-635. http://dx.doi.org/10.4039/n06-012

Maes K. 1984. Some remarks on the genus Euproctis Hübner, [1819] 1816 (Lepidoptera: Lymantriidae). Nota Lepidopterologica, 7 (1): 55-58.

Mitchell A., Mitter C. \& Regier J.C. 2006. Systematics and evolution of the cutworm moths (Lepidoptera: Noctuidae). Evidence from two protein-coding nuclear genes. Systematic Entomology, 31: 21-46. http:// dx.doi.org/10.1111/j.1365-3113.2005.00306.x

Seitz A. 1943 (édition française). Les Macrolépidoptères du Globe. Tome XIV. E. Le Moult, Paris.

Strand E. 1922. Arctiidae: Subfam. Lithosiinae. In: Wagner H. (ed.), Lepidopterorum Catalogus, 15-16 (26): 501-899. Junk, Berlin \& The Hague.

Tikhomirov A.M. 1979. The phylogenetic relationship and classification of European Arctiidae (Lepidoptera) as indicated by the functional morphology of the male genitalia. Entomological Review, 58: 63-69.

Tuxen S.L. 1970. Taxonomist's Glossary of Genitalia in Insects. $2^{\text {nd }}$ edition. Munksgaard, Copenhagen.

Vári L., Kroon D.M. \& Krüger M. 2002. Classification and checklist of the species of Lepidoptera recorded in Southern Africa. Published by the authors. Sasolburg, South Africa.

Weller S., Da Costa M., Simmons R., Dittmar K. \& Whiting M. 2009. Evolution and Taxonomic Confusion in Arctiidae. In: Conner W.E. (ed.) Tiger moths and Woolly Bears, Behavior, ecology, and evolution of the Arctiidae: 11-30. Oxford University Press, Oxford.

Zahiri R., Kitching I.J., Lafontaine J.D., Mutanen M., Kaila L., Holloway J.D. \& Wahlberg N. 2010. A new molecular phylogeny offers hope for a stable family level classification of the Noctuoidea (Lepidoptera). Zoologica Scripta: 1-16.

Manuscript received: 12 March 2012

Manuscript accepted: 6 September 2012

Published on: 20 September 2012

Topic editor: Koen Martens

In compliance with the $I C Z N$, printed versions of all papers are deposited in the libraries of the institutes that are members of the EJT consortium: Muséum National d'Histoire Naturelle, Paris, France; National Botanic Garden of Belgium, Meise, Belgium; Royal Museum for Central Africa, Tervuren, Belgium; Natural History Museum, London, United Kingdom; Royal Belgian Institute of Natural Sciences, Brussels, Belgium; Natural History Museum of Denmark, Copenhagen, Denmark. 